\title{
Recovery in patients with major depressive disorder (MDD): results of a 6-month, multinational, observational study
}

This article was published in the following Dove Press journal:

Patient Preference and Adherence

3I October 2017

Number of times this article has been viewed

\author{
Diego Novick' \\ William Montgomery ${ }^{2}$ \\ Ellen Vorstenbosch ${ }^{3}$ \\ Maria Victoria Moneta ${ }^{3}$ \\ Héctor Dueñas ${ }^{4}$ \\ Josep Maria Haro 3 \\ 'Eli Lilly and Company, Windlesham, \\ Surrey, UK; ${ }^{2}$ Eli Lilly Australia Pty Ltd, \\ West Ryde, NSW, Australia; ${ }^{3}$ Parc \\ Sanitari Sant Joan de Déu, Fundació \\ Sant Joan de Déu, CIBERSAM, \\ Universitat de Barcelona, Barcelona, \\ Spain; ${ }^{4}$ Eli Lilly de Mexico, Mexico \\ City, Mexico
}

Correspondence: Diego Novick Eli Lilly and Company, Lilly Research Centre, Erl Wood Manor, Sunninghill Road, Windlesham, Surrey,

GU20 6PH, UK

Tel +44 I 276483832

Fax +44 I276 483I92

Email novick_diego@lilly.com

\begin{abstract}
Not all individuals treated for major depressive disorder (MDD) achieve recovery. This observational study examined the recovery rates in MDD patients and the patient characteristics associated with achieving recovery in a naturalistic clinical setting. Recovery was defined as having both clinical and functional remission. Data for this post hoc analysis were taken from a 24-week prospective, observational study that involved 1,549 MDD patients. Clinical remission was assessed using the 16-item Quick Inventory of Depressive Symptomatology Self-Report and functional remission through the Sheehan Disability Scale and no days of reduced productivity in the previous week. Generalized estimating equation regression models were used to examine the baseline factors associated with recovery during follow-up. Clinical and functional remission was achieved in $70.6 \%$ and $56.1 \%$ of the MDD patients, respectively. MDD patients who achieved recovery (52.1\%) were significantly less likely to have impaired levels of functioning, concurrent medical or psychiatric conditions, low levels of education, or nonadherence to therapy at follow-up. The level of functioning during the index episode seems to be a better predictor of recovery than symptom severity. Therefore, the level of functioning should be considered while determining recovery from depression.
\end{abstract}

Keywords: remission, functional impairment, clinical remission, course of illness, disability, predictors

\section{Introduction}

Major depressive disorder (MDD) is a highly prevalent psychiatric condition that is associated with significant levels of disability, morbidity, and mortality. ${ }^{1,2}$ Treatment of MDD traditionally aims to reduce depressive symptoms. ${ }^{3}$ Consequently, the treatment is considered fully effective when complete or near-complete absence of the MDD symptoms (for a certain period of time) is achieved. ${ }^{4}$ However, MDD is associated with major and sometimes long-lasting decreased levels of functioning and productivity. Approximately $60 \%$ of the patients with an MDD report severe or very severe functional impairment ${ }^{1}$ and can continue to experience (partial) impairment long after mood symptoms have been resolved. ${ }^{5}$ Moreover, patients in remission report better functioning than those with mild depression, although their functioning is significantly worse than that found in the general population. ${ }^{6}$ Therefore, remission of symptoms does not necessarily coincide with completely restored levels of functioning. Furthermore, MDD symptoms have differential effects on the level of functioning; depressed mood and loss of interest are strongly related to impaired functioning while weight problems, mid-nocturnal insomnia, and hypersomnia have less impact. ${ }^{7}$ 
There is no commonly agreed definition of remission and recovery in MDD. Remission has been defined as a period of time in which the patient no longer meets the symptomatic criteria for the disorder or has only mild symptoms. Recovery is usually defined as sustained remission for a longer period of time. The operational criteria encompass 1) severity of symptoms assessed through symptom measurement instruments (eg, the Hamilton Depression Rating Scale; HAM-D $\left.{ }_{17}\right)^{8,9}$ and 2) duration or a certain period of time. ${ }^{10}$ A reduction in symptom severity of $\geq 50 \%$ during the course of treatment became an indicator of clinical response, that is, a clinically significant improvement. ${ }^{11}$ A cutoff score on one of these measurements (eg, HAM-D $\left.{ }_{17} \leq 7\right)^{12}$ is subsequently used to determine remission. ${ }^{13,14}$ However, specific symptoms considered and symptom intensity may vary across studies. ${ }^{15}$

Despite reduction in symptom severity, most patients report residual symptoms and continued impaired functioning. ${ }^{15,16}$ A survey-based study revealed that the absence of MDD symptoms was only one and a less important factor, according to patients, in determining remission; more important factors were the presence of positive mental health (eg, optimism, vigor, self-confidence), a return to one's usual self, and a general sense of well-being. ${ }^{17}$ In other mental disorders such as schizophrenia, quality of life and level of functioning are at least as relevant as residual symptoms in defining recovery. ${ }^{18}$ In MDD treatment, despite an emerging awareness, $15,16,19,20$ functioning and well-being are often neglected in recovery measures. In determining recovery, a multidimensional outcome of MDD treatment should therefore be considered, characterized by symptom severity (clinical remission) as well as level of functioning (functional remission).

Previous studies have identified predictors of recovery from MDD. However, most of these studies defined recovery as "absence of symptoms" or "no more than mild symptoms" rather than the achievement of both clinical and functional remission over a certain period of time. Increased likelihood of recovery, here considered as clinical remission, is associated with less severe depressive symptoms, lower anxiety scores, and lower levels of personality dysfunction, ${ }^{21,22}$ whereas factors such as lower economic status, measured by education, income, or occupation, concurrent psychiatric and medical conditions, longer duration of index episode, and older age are associated with a decreased likelihood or delayed achievement of clinical remission. ${ }^{23-25}$

The objectives of this exploratory study were to examine the recovery rates (defined as having both clinical and functional remission) in MDD patients, to describe the characteristics of MDD patients who do achieve recovery and those who do not and to examine the baseline characteristics associated with recovery from MDD in a naturalistic 24-week prospective, observational study.

\section{Materials and methods Study setting/design}

This is a post hoc analysis of data from a 6-month, prospective, observational study aiming to examine treatmentemergent sexual dysfunction (TESD) and other treatment outcomes among patients with MDD who were treated with either a selective serotonin reuptake inhibitor (SSRI) or a serotonin-norepinephrine reuptake inhibitor (SNRI) in actual clinical practice. Between November 15, 2007, and November 28, 2008, a total of 1,647 patients at 88 sites were enrolled in the study. Of these, 1,549 patients were classified as "sexually active patients without sexual dysfunction at study entry." The patients were from the following countries and regions: East Asia (China [ $\mathrm{n}=205 ; 13.2 \%]$, Hong Kong $[\mathrm{n}=18 ; 1.2 \%]$, Malaysia $[\mathrm{n}=33 ; 2.1 \%]$, the Philippines $[n=113 ; 7.3 \%]$, Taiwan $[n=199 ; 12.8 \%]$, Thailand $[n=17$; $1.1 \%]$, and Singapore $[\mathrm{n}=2 ; 0.1 \%]$ ), the Middle East (Saudi Arabia $[\mathrm{n}=179 ; 11.6 \%]$ and United Arab Emirates [ $\mathrm{n}=135$; $8.7 \%]$ ), Mexico $(\mathrm{n}=591 ; 38.2 \%)$, and other regions (Israel $[n=9 ; 0.6 \%]$ and Austria $[n=48 ; 3.1 \%])$. The study was conducted in accordance with the ethical principles that have their origin in the Declaration of Helsinki ${ }^{26}$ and, where applicable to a study of this nature, are consistent with the International Conference on Harmonization Guideline for Good Clinical Practice. ${ }^{27}$ The ethical standards of responsible local committees and the regulations of the participating countries were followed, and wherever required by local law, Ethical Review Board (ERB) approval as required for observational studies was obtained. The list of ERBs is provided as Supplementary material (Table S1). All patients provided informed consent for the provision and collection of the data. Further details about the study design have been published elsewhere. ${ }^{28,29}$

\section{Participants}

For the purpose of this exploratory study, 1,549 patients (outpatients) met the inclusion criteria at baseline: 1) presenting with an episode of MDD within the normal course of care, with MDD diagnosed according to the International Statistical Classification of Diseases 10th revision (ICD-10) ${ }^{30}$ or Diagnostic and Statistical Manual of Mental Disorders 4th edition text revision (DSM-IV-TR) ${ }^{31}$ criteria; 2) at least moderately depressed, defined by Clinical Global Impressions of Severity (CGI-S; ${ }^{32}$ ie, CGI-S score $\geq 4$ ); 3 ) initiating, or switching to, any available SSRI or SNRI antidepressant at a 
treating psychiatrist's discretion; 4) age $\geq 18$ years; 5) being "sexually active without sexual dysfunction at study entry" as defined by the Arizona Sexual Experience Scale (ASEX;33 ie, the criteria for sexual dysfunction: ASEX total score $\geq 19$, ASEX score $\geq 5$ on any item, or ASEX score $\geq 4$ on any three items); and 6) not being currently enrolled in another ongoing study. Patients were excluded from participation if they had 1) a history of treatment-resistant depression; 2) a past or current diagnosis of major mental disorders (eg, schizophrenia-related, bipolar disorder, dementia, or mental retardation); or 3 ) received any antidepressant within 1 week (1 month for fluoxetine) prior to study entry, with the exception of patients receiving an ineffective treatment for whom the immediate switch to an SSRI or SNRI antidepressant was considered to be the best treatment option.

\section{Data collection and outcome assessment}

Data were collected during visits within the normal course of care. The routine outpatient visit at which patients were enrolled served as the time for baseline data collection. Subsequent data collection was targeted at weeks 8,16 , and 24 following the baseline visit. Patient demographics and clinical history were recorded in the baseline assessment. Clinical severity of depression was assessed by the treating psychiatrists at each visit using the CGI-S and the 16-item Quick Inventory of Depressive Symptomatology Self-Report $\left(\right.$ QIDS-SR $\left._{16}\right) \cdot{ }^{34}$ Higher scores mean greater clinical severity. Clinical remission was defined as a QIDS-SR $_{16}$ score $\leq 5$. This is more or less equivalent to a score of $\leq 7$ on the HAM-D ${ }_{17}{ }^{8,9}$ The Integral Inventory for Depression (IID) ${ }^{35}$ was used to measure the emotional and painful symptoms of MDD. The IID integrates the emotional items from the Mental Health Inventory-5 (MHI-5) ${ }^{36}$ and the pain-related items from the Somatic Symptom Inventory (SSI) ${ }^{37}$ which was modified to add items 27 (joint pain) and 28 (neck pain). ${ }^{20}$ Functioning was measured with the Sheehan Disability Scale (SDS) ${ }^{38}$ which evaluates on a scale from 0 to 10 the disability experienced by the individual regarding family life/home, social life/leisure activities, and work/school. The total SDS score was the sum of the three items with higher scores meaning greater disability/lower functioning. Functional remission was defined as having no or minimum disability on the SDS (score $<3$ on each of the three subscales) and no days of reduced productivity in the previous week. This is a modification of the definition of functional remission by Sheehan et al since they based their criteria solely on the SDS scores. ${ }^{5}$ Questionnaires were administered by the participating investigators in the local language; if unavailable, the questionnaires were translated/adapted to different languages. Recovery was defined as having both clinical and functional remission. If data are missing for at least one of three subscales or days of reduced productivity, then functional remission will be missing. Likewise, if data on remission or functional remission are missing, recovery will be missing. From visit 2 onwards, patients were asked, with a single item, about their treatment adherence since last assessment. Possible responses were: I never missed taking my medication; I missed only a couple of times, but basically took all the medicine; I missed the medicine several times, but took at least half of it; I took less than half of what was prescribed; and I stopped taking the medicine altogether. Patients were considered treatment adherent if they reported never having missed taking their medication. All the assessment scales have been tested in adult patients with MDD, and the psychometric properties have been reported to be adequate to excellent. ${ }^{33,34,39-42}$

\section{Statistical analysis}

This post hoc study examined baseline predictors of recovery defined as clinical and functional remission (ie, measured at each post-baseline visit) in the treatment of MDD. Of the 1,549 patients, 1,297 were included in these post hoc analyses because they were not in clinical remission at baseline (ie, QIDS-SR ${ }_{16}$ score $>5$ ), had at least one post-baseline QIDS$\mathrm{SR}_{16}$ assessment and initiated treatment with either duloxetine or an SSRI as "monotherapy" (this last criterion was included for reasons of consistency with previous analyses).

For each measurement, the proportion of patients who were in clinical remission, functional remission, or recovery was calculated (using the number of patients with no remission at baseline as denominator). Baseline characteristics as well as outcomes of patients who did achieve recovery at some point during the study were described and compared using chi-square test (categorical variables) and Mann-Whitney $U$ test or Kruskal-Wallis test (continuous variables).

Generalized estimating equation (GEE) regression models with exchangeable correlation structure were used to examine the baseline factors associated with recovery during follow-up. The models included recovery as a timevarying dependent variable, and the following explanatory variables were measured at baseline: age (years), gender (male/female), QIDS-SR ${ }_{16}$ total score, SDS total score, region (East Asia/the Middle East/Mexico/other region), and baseline treatment (duloxetine/SSRI). In addition, the following baseline variables were included if they appeared to be significant at $p<0.1$ in univariate GEE analyses (ie, one 
explanatory variable at a time): age at first episode of MDD (years), marital status (married or living together/never married/other), independent living (yes/no), educational attainment ( $\leq$ primary school/secondary school or occupational program/ $\geq$ university), employment status (full-time/ economically inactive/unemployed or part-time), having had MDD episodes in the 24 months prior to baseline (yes/no), having any significant psychiatric or medical comorbidity ( $>1 / 1 /$ none; eg, alcohol abuse, alcohol dependence, cardiovascular disease, cancer, chronic pain, chronic movement disabilities, endocrine disorder, diabetes mellitus, gastrointestinal disorder, neurological disorder, substance abuse, or substance dependence), having any painful physical symptom at baseline (yes/no), and adherence at visit 2 (yes/no).

\section{Results}

\section{Descriptive demographic and clinical information}

The demographic details and clinical characteristics of 1,297 patients who entered the study at baseline are presented in Table 1. Overall, mean (SD) age of the 1,297 participants was 38 (10.6) years, and 56.4\% were female. The mean (SD) scores were 4.54 (0.68; CGI-S) and 14.65 (4.53; QIDS-SR 16 ) on clinical severity and 17.78 (6.36; SDS) on disability.

Of the 1,297 participants who entered the study at baseline, 1,172 (90.4\%) were also assessed at 8 weeks, $1,128(87.0 \%)$ at 16 weeks, and $1,018(78.5 \%)$ at 24 weeks. The course of clinical remission, functional remission, and recovery is shown in Figure 1; the proportions of patients (using the number of patients at baseline as denominator) who achieved clinical remission, functional remission, and recovery at 8,16 , and 24 weeks follow-up are shown. At week $8,39.2 \%$ of the patients achieved clinical remission, while $19.5 \%$ of the patients achieved functional remission and $15.9 \%$ recovery. A comparable pattern was found at week 16 of follow-up: $52.9 \%$ showed clinical remission but the proportion of patients with functional remission $(37.7 \%)$ and recovery (34.2\%) lagged behind. At week 24, clinical remission was seen in $58.7 \%$ of the patients and functional remission and recovery in $47.9 \%$ and $44.9 \%$ of the patients, respectively.

During the entire follow-up period ( 24 weeks), a total of 916 patients $(70.6 \%)$ achieved clinical remission at some point during the study and $73.0 \%$ of them also achieved recovery. Functional remission was achieved at some point by 719 patients $(56.1 \%)$ and $92.9 \%$ achieved recovery as well. Overall, 668 patients (52.1\%) achieved recovery (ie, clinical and functional remission) at some point during the study period.
Table I Patient characteristics at study entry (baseline)

\begin{tabular}{|c|c|c|}
\hline Baseline characteristic & $\mathbf{n}$ & $\%$ \\
\hline Age, mean (SD), years & \multicolumn{2}{|c|}{$38.0(10.6)$} \\
\hline \multicolumn{3}{|l|}{ Gender } \\
\hline Male & 566 & 43.64 \\
\hline Female & 731 & 56.36 \\
\hline Independent living & 214 & 16.50 \\
\hline \multicolumn{3}{|l|}{ Marital status } \\
\hline Married, living together & 853 & 65.77 \\
\hline Never married & 157 & 12.10 \\
\hline Other & 287 & 22.13 \\
\hline \multicolumn{3}{|l|}{ Educational attainment } \\
\hline$\leq$ Primary school & 107 & 8.25 \\
\hline Secondary school/occupational program & 572 & 44.10 \\
\hline$\geq$ University & 618 & 47.65 \\
\hline \multicolumn{3}{|l|}{ Employment status } \\
\hline Full-time & 718 & 55.36 \\
\hline Economically inactive & 338 & 26.06 \\
\hline Unemployed/part-time & 241 & 18.58 \\
\hline Had MDD episode in last 24 months & 844 & 65.07 \\
\hline \multicolumn{3}{|c|}{ Number of comorbidities (psychiatric and medical) } \\
\hline None & 955 & 74.03 \\
\hline 1 & 258 & 20.00 \\
\hline$>1$ & 77 & 5.97 \\
\hline Painful physical symptoms & 680 & 52.47 \\
\hline Adherence (at visit 2-8 weeks) & 803 & 68.5 \\
\hline IID total score, mean (SD) & \multicolumn{2}{|c|}{$35.54(7.09)$} \\
\hline CGI-S score, mean (SD) & \multicolumn{2}{|c|}{$4.54(0.68)$} \\
\hline QIDS-SR $_{16}$ score, mean (SD) & \multicolumn{2}{|c|}{$14.65(4.53)$} \\
\hline SDS score, mean (SD) & \multicolumn{2}{|c|}{$17.78(6.36)$} \\
\hline
\end{tabular}

Note: Data are presented as percentage or mean (standard deviation) as appropriate.

Abbreviations: SD, standard deviation; MDD, major depressive disorder; CGI-S, Global Impressions of Severity; QIDS-SR ${ }_{16}$, 16-item Quick Inventory of Depressive Symptomatology Self-Report; SDS, Sheehan Disability Scale; IID, Integral Inventory for Depression.

\section{Baseline characteristics of patients who achieved recovery at some point during follow-up}

To examine recovery, the baseline characteristics of the patients who achieved recovery at some point during follow-up $(\mathrm{n}=668 ; 52.1 \%)$ were compared with those who did not achieve recovery at any time point ( $n=614 ; 47.9 \%$; Table 2$)$. Compared with patients who did not achieve recovery during follow-up, patients who did achieve it reported lower levels of disability, indicating a higher level of functioning at baseline (measured using SDS; $p=0.0008$ ). In addition, patients achieving recovery were more likely to be female ( $p=0.0295)$, to be married or living together $(p=0.0190)$, to have a higher level of education ( $p=0.0075$ ), to be older at their first MDD episode 
A

Clinical remission

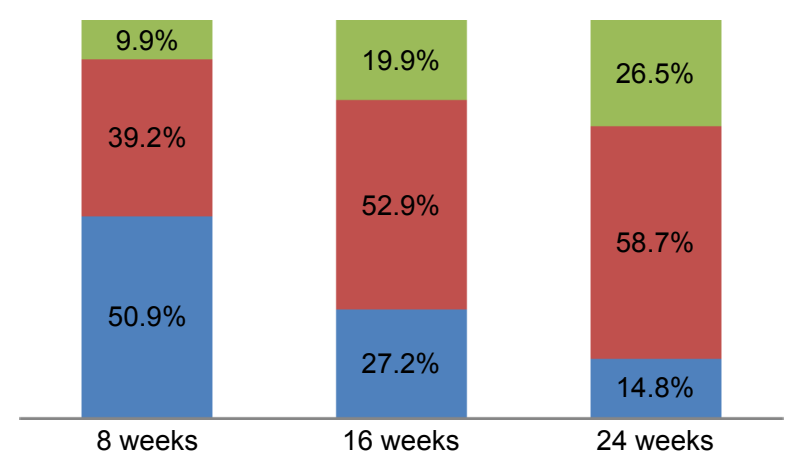

No clinical remission $\square$ Clinical remission $\square$ Not evaluated

\section{B \\ Functional remission}

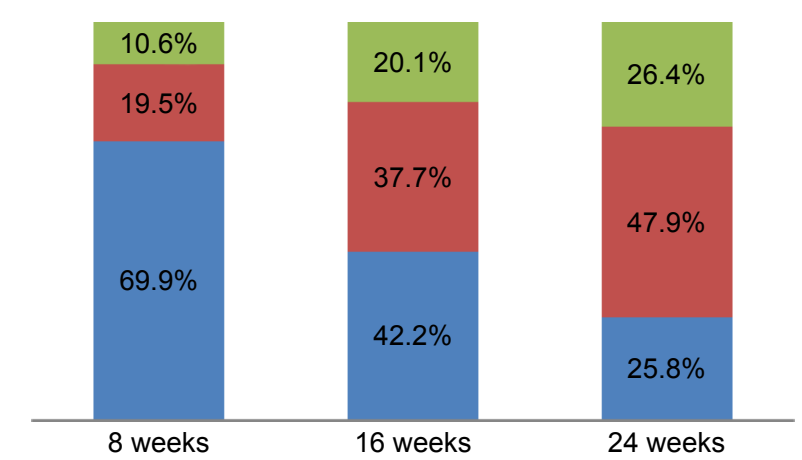

No functional remission $\quad$ Functional remission $\quad$ Not evaluated

Recovery

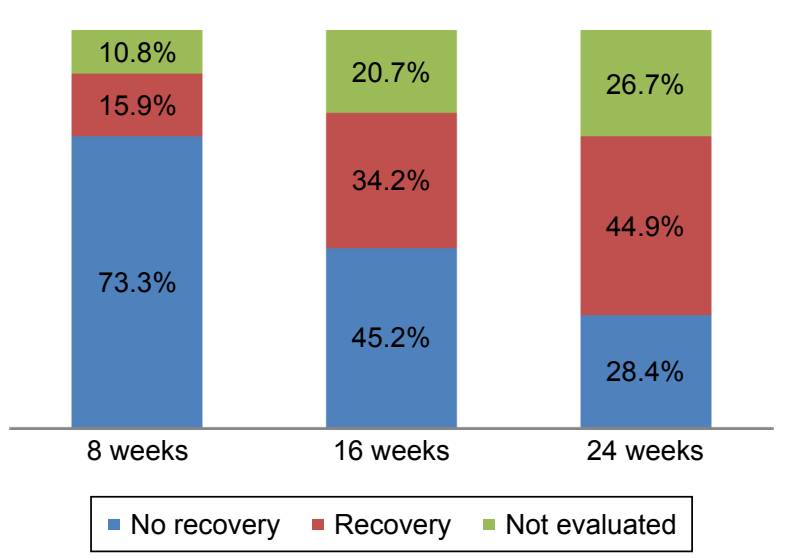

Figure I Proportion of patients with (A) clinical remission, (B) functional remission and (C) recovery during follow-up based on total patients at baseline.

( $p=0.0023$ ), and to be adherent to therapy (visit at week 8; $p<0.0001$ ). On the other hand, they were less likely to have had an episode of MDD in the last 24 months $(p<0.0001)$ or to have concurrent psychiatric and medical conditions $(p<0.0001)$ and painful depression-related physical symptoms ( $p=0.0342$ ). No significant differences were found regarding the level of clinical severity measured using either the CGI-S $(p=0.2304)$ or the QIDS-SR $_{16}(p=0.4771)$.

The results of multiple (GEE) regression, which examined the baseline patient characteristics associated with recovery and included separate observations for different follow-up visits during the 24-week study period, are shown in Table 3. The associations described above were largely maintained in this logistic regression analysis, except for marital status and age at first MDD episode. Patients who at baseline had higher levels of disability (odds ratio $[\mathrm{OR}]=0.95 ; p<0.001$ ), concurrent medical or psychiatric conditions $(\mathrm{OR}=0.70,1$ vs no comorbid condition; $p=0.011$ and $\mathrm{OR}=0.26,>1$ vs no comorbid condition; $p<0.001$ ), lower levels of education $(\mathrm{OR}=0.52$ primary school vs university; $p=0.006$ and $\mathrm{OR}=0.76$ secondary school/occupational program vs university; $p=0.016)$ and who were nonadherent to therapy at week $8(\mathrm{OR}=0.52 ; p<0.001)$ were less likely to achieve recovery at some point during the follow-up.

\section{Discussion}

This study has shown that when patient functioning is taken into account, recovery rates for MDD are substantially lower than when the definition of recovery is based exclusively on the clinical symptoms of depression. The main factors associated with the achievement of recovery were adherence to treatment, higher levels of education, absence of comorbid medical or psychiatric conditions, and lower levels of functional impairment during the index episode.

Regarding the factors associated with recovery, our findings are largely consistent with those reported in other studies. Nonadherence has previously been recognized as an important factor in negative treatment outcomes in MDD. ${ }^{43,44}$ Moreover, the treatment adherence rates in our study were within the range of those reported elsewhere. ${ }^{45,46}$ In any case, 
Table 2 Baseline characteristics of patients who did and did not achieve recovery at some point during follow-up

\begin{tabular}{|c|c|c|c|}
\hline Baseline characteristic & $\begin{array}{l}\text { Recovery } \\
(n=668)\end{array}$ & $\begin{array}{l}\text { No recovery } \\
(n=6 \mid 4)\end{array}$ & $p$-value \\
\hline Age, mean (SD), years & $37.70(10.07)$ & $38.25(11.00)$ & 0.5710 \\
\hline Gender, \% & & & 0.0295 \\
\hline Male & 40.9 & 46.9 & \\
\hline Female & 59.1 & 53.1 & \\
\hline Independent living, \% & & & 0.8735 \\
\hline Yes & 16.6 & 16.3 & \\
\hline No & 83.4 & 83.7 & \\
\hline Marital status, $\%$ & & & 0.0190 \\
\hline Married, living together & 69.5 & 62.4 & \\
\hline Never married & 11.7 & 12.9 & \\
\hline Other & 18.9 & 24.8 & \\
\hline Educational attainment, \% & & & 0.0075 \\
\hline$\leq$ Primary school & 6.3 & 9.4 & \\
\hline Secondary school/occupational program & 42.1 & 46.7 & \\
\hline$\geq$ University & 51.6 & 43.8 & \\
\hline Employment status, \% & & & 0.0664 \\
\hline Full-time & 57.2 & 54.6 & \\
\hline Economically inactive & 26.9 & 24.6 & \\
\hline Unemployed/part-time & 15.9 & 20.8 & \\
\hline Age at first episode of MDD, mean (SD), years & $34.45(10.63)$ & $32.97(11.82)$ & 0.0023 \\
\hline Had MDD episode in last 24 months, $\%$ & 59.7 & 70.7 & $<0.001$ \\
\hline Number of comorbidities (psychiatric and medical), \% & & & $<0.001$ \\
\hline None & 79.6 & 69.0 & \\
\hline I & 18.2 & 21.3 & \\
\hline$>1$ & 2.3 & 9.7 & \\
\hline Painful physical symptoms, \% & 49.6 & 55.5 & 0.0342 \\
\hline Adherence (at visit 2-8 weeks), \% & 77.3 & 57.4 & $<0.001$ \\
\hline CGI-S, mean (SD) & $4.57(0.70)$ & $4.51(0.65)$ & 0.2304 \\
\hline QIDS-SR $_{16}$, mean $(S D)$ & $14.43(4.14)$ & $14.73(4.8 I)$ & 0.4771 \\
\hline SDS, mean (SD) & $17.20(6.17)$ & $18.26(6.46)$ & 0.0008 \\
\hline
\end{tabular}

Note: Data are presented as percentage or mean (standard deviation) as appropriate.

Abbreviations: SD, standard deviation; MDD, major depressive disorder; CGI-S, Global Impressions of Severity; QIDS-SR ${ }_{16}$, I6-item Quick Inventory of Depressive Symptomatology Self-Report; SDS, Sheehan Disability Scale.

whether recovery is defined as clinical remission or also takes into account the patient's level of functioning, this study underlines the fact that nonadherence to treatment has a negative impact on the course of depression.

Additionally, the likelihood of achieving recovery was negatively associated with lower levels of education. Previous studies have shown that lower socioeconomic status measured either as level of education or as income is associated with an increased risk of an enduring MDD. ${ }^{23,47}$

The results show that medical or psychiatric comorbid conditions negatively affect the course of depression. Previous studies have found that $60 \%-70 \%$ of the MDD patients have at least one comorbid psychiatric condition and that about two thirds report one concurrent medical condition. ${ }^{24}$ Though the presence of comorbidities was lower in this study, it still indicated a decreased likelihood of recovery from depression. This is in line with other studies in which comorbid medical conditions as well as psychiatric illnesses such as anxiety disorder, dysthymia, personality disorder, and substance abuse exerted a negative effect on the course of depression. ${ }^{21,22,25,47}$ Furthermore, a considerable proportion of the MDD patients in this study reported painful depressionrelated physical symptoms. These have been associated with increased severity of MDD and reduced quality of life. ${ }^{20}$

Remarkably, the level of functioning during the index episode was a predictor of achieving recovery while symptomatic severity was not. MDD patients with lower levels of functioning at their baseline visit were less likely to achieve recovery. This association did not exist for clinical severity; the statistical model, adjusted for the influence of other factors, showed that baseline clinical severity was not a predictor of recovery. Most studies of recovery do not consider baseline functioning as a predictor. In a study on adolescents with MDD in which recovery was defined 
Table 3 Baseline factors associated with recovery during follow-up

\begin{tabular}{|c|c|c|}
\hline Variables & $\begin{array}{l}\text { Adjusted OR } \\
(95 \% \mathrm{Cl})^{*}\end{array}$ & $p$-value \\
\hline Higher QIDS-SR ${ }_{16}$ score & $1.00(0.97-1.03)$ & 0.945 \\
\hline Higher SDS score & $0.95(0.93-0.97)$ & $<0.001$ \\
\hline Being older & $1.00(0.99-1.01)$ & 0.795 \\
\hline Being male (vs female) & $1.01(0.81-1.26)$ & 0.947 \\
\hline \multicolumn{3}{|l|}{ Weeks (vs 8) } \\
\hline 16 & $3.88(3.28-4.58)$ & $<0.001$ \\
\hline 24 & $8.59(7.07-10.45)$ & $<0.001$ \\
\hline \multicolumn{3}{|l|}{ Educational attainment (vs $\geq$ university) } \\
\hline Secondary school/occupational program & $0.76(0.61-0.95)$ & 0.016 \\
\hline$\leq$ Primary school & $0.52(0.33-0.83)$ & 0.006 \\
\hline Having had MDD episodes in the past & $0.83(0.66-1.04)$ & 0.107 \\
\hline \multicolumn{3}{|l|}{24 months (vs not) } \\
\hline \multicolumn{3}{|l|}{ Having significant comorbidities at baseline } \\
\hline I & $0.70(0.53-0.92)$ & 0.011 \\
\hline$>1$ & $0.26(0.14-0.48)$ & $<0.001$ \\
\hline Having painful physical symptoms & $0.97(0.78-1.21)$ & 0.776 \\
\hline Being nonadherent to treatment at week 8 & $0.52(0.4 \mathrm{I}-0.67)$ & $<0.001$ \\
\hline
\end{tabular}

Note: *This logistic regression model with repeated measures included recovery as a time-varying variable during follow-up and also adjusted for region and baseline treatment.

Abbreviations: OR, odds ratio; MDD, major depressive disorder; QIDS-SR ${ }_{16}$, 16-item Quick Inventory of Depressive Symptomatology Self-Report; SDS, Sheehan Disability Scale.

as clinical remission lasting for at least 8 weeks, severe evaluator-rated depression and higher global functioning were identified as predictors. ${ }^{21}$ In another study, in which severity of depression and global functioning (GAF) were associated with recovery, they could not be identified as predictors of recovery. ${ }^{47}$ These incongruent outcomes might be explained by the presence of residual symptoms during clinical recovery. ${ }^{15,16}$ Moreover, studies with MDD patients in clinical remission have shown that the severity of residual symptoms was strongly adversely associated with the level of functioning. ${ }^{6}$ Future research should be designed to clarify the relationship between residual symptoms and the impaired functioning of MDD patients in clinical remission.

The present study defined recovery in terms of achieving clinical as well as functional remission. Traditionally, recovery has been defined as maintenance of clinical remission over a defined period of time. This definition assumes that remission of MDD-related symptoms occurs in parallel with functional improvement. However, this study has demonstrated that this is not the case. In accordance with a study by Sheehan et al, ${ }^{5}$ the proportion of MDD patients who achieved clinical remission was higher than the proportion who achieved functional remission, or recovery operationalized as achievement of both clinical and functional remission. Although it is not clear why our remission rates were higher than those published by Sheehan et al, ${ }^{5}$ one possible explanation may be found in the characteristics of our patient sample: our observational study was designed primarily to examine the frequency of TESD in the treatment of MDD and thus included only those patients who were sexually active without sexual dysfunction at baseline. It is possible that such MDD patients have a better MDD prognosis than those with sexual dysfunction.

This study controlled for the effect of medication (duloxetine/SSRI) on the course of MDD. However, previous findings showed that, compared with SSRI-treated patients, duloxetine-treated patients were more likely to achieve clinical remission. ${ }^{48}$ Likewise, duloxetine-treated patients showed significantly more improvement in the level of functioning than SSRI-treated patients. ${ }^{49}$ More research is needed to clarify whether duloxetine-treated patients are more likely to achieve recovery (ie, clinical and functional remission) than their SSRI-treated counterparts, especially as some studies report superiority of SNRI (including duloxetine) over SSRI treatment, ${ }^{50-52}$ whereas others report no clinically meaningful differences for either medication. ${ }^{31,53,54}$

The primary outcomes of this study are based on patientrated measurements. Patient-rated measurements can provide relevant information for treatment evaluation, ${ }^{55}$ and previous research has shown that patient- and clinician-rated measurements are complementary in the assessment of MDD. ${ }^{56,57}$ Nevertheless, patients and clinicians may differ in their valuation and assessment of treatment outcomes. ${ }^{58}$ Accordingly, the use of self-report measures can be considered a limitation when compared with assessment by a clinician, although it is also a strength since it provides a better representation of patients' perspectives.

Our definition of recovery deserves some discussion. We defined recovery as a low level of symptoms with no impaired functioning. Other conceptualizations, which have been mostly applied to severe mental illness, define recovery as the development of new meaning and purpose in one's life as one grows beyond the catastrophic effects of psychiatric disability ${ }^{59-61}$ Nevertheless, in line with other studies on recovery of $\mathrm{MDD}^{5,6}$ or severe mental illness, ${ }^{62,63}$ the course of clinical remission seems to differ from the course of functional remission. Our findings indicate that MDD treatment and evaluation should take into account not only symptomatic severity but also the level of impaired functioning. Clinical and functional remission might be associated with different baseline factors and may respond to different treatment strategies. Clinical trials should also consider functioning in addition to symptomatic severity in the assessment of patient outcomes. 
The present study has some limitations. First, as mentioned above, this study included only those patients who were sexually active without sexual dysfunction at baseline as the primary objective was to assess the frequency of TESD in the treatment of MDD. Sexual dysfunction has been reported to be two to three times more prevalent in patients with depression compared with the general population, ${ }^{64,65}$ and thus our findings may not be immediately generalizable to MDD patients as a whole. Further research is warranted to examine whether these findings can be replicated in MDD patients without such selection criteria. Second, although our study prospectively assessed the severity of depression and level of functioning in a "real-world" setting, the associations found in our study may not imply causal relationships given its observational design. Third, although this observational study included more than 1,000 patients from various countries, they may not be representative of the patients with MDD in each region. Additionally, as the study was not designed for that purpose, we did not analyze the cultural differences. However, we adjusted for country as a covariate in all analyses. Finally, these exploratory analyses were not adjusted for a multiplicity of factors; this study should be considered hypothesis-generating, not hypothesis-testing.

In conclusion, the present study showed that the level of functioning during the index episode of MDD might be a better predictor of recovery than symptom severity. Therefore, it is highly recommended that both symptom severity and level of functioning are considered while determining recovery in patients with an MDD.

\section{Acknowledgment}

This work was supported by Eli Lilly and Company.

\section{Disclosure}

Diego Novick, William Montgomery, and Héctor Dueñas are employees of Eli Lilly and Company. Josep Maria Haro has acted as a consultant, received grants, or acted as a speaker in activities sponsored by the following companies: Astra-Zeneca, Eli Lilly and Company, Otsuka, and Lundbeck. Maria Victoria Moneta conducted the statistical analysis under a contract between CIBERSAM and Eli Lilly and Company. The authors report no other conflicts of interest in this work.

\section{References}

1. Kessler RC, Berglund P, Olga Demler M, Al E. The epidemiology of major depressive disorder results from the National Comorbidity Survey Replication (NCS-R). JAMA. 2003;289(23):3095-3105.

2. Ferrari AJ, Charlson FJ, Norman RE, et al. Burden of depressive disorders by country, sex, age, and year: findings from the global burden of disease study 2010. PLoS Med. 2013;10(11):e1001547.
3. Rush AJ, Kraemer HC, Sackeim HA, et al. Report by the ACNP task force on response and remission in major depressive disorder. Neuropsychopharmacology. 2006;31(9):1841-1853.

4. Thase ME. Effectiveness of antidepressants: comparative remission rates. J Clin Psychiatry. 2003;64(Suppl 2):3-7.

5. Sheehan DV, Harnett-Sheehan K, Spann ME, Thompson HF, Prakash A. Assessing remission in major depressive disorder and generalized anxiety disorder clinical trials with the discan metric of the Sheehan disability scale. Int Clin Psychopharmacol. 2011;26(2):75-83.

6. Sacchettia E, Franke E, Siracusanoc A, Racagnid G, Vitaa A, Turrina C. Functional impairment in patients with major depression in clinical remission: results from the VIVAL-D-Rem, a nationwide, naturalistic, cross-sectional survey. Int Clin Psychopharmacol. 2015;30(3): 129-141.

7. Fried EI, Nesse RM. The impact of individual depressive symptoms on impairment of psychosocial functioning. PLoS One. 2014;9(2): e90311.

8. Hamilton M. A rating scale for depression. J Neurol Neurosurg Psychiatry. 1960;23(1):56-63.

9. Ciraulo D, Evans J, Qiu W, Shader R, Salzman C. Pharmacotherapy of Depression. 2nd ed. (Ciraulo D, Shader RI, editors). New York: Human Press; 2011.

10. Keller MB. Remission versus response: the new gold standard of antidepressant care. J Clin Psychiatry. 2004;65(Suppl 4):53-59.

11. Cusin C, Yang H, Yeung A, Fava M. Handbook of Clinical Rating Scales and Assessment in Psychiatry and Mental Health. 2010.

12. Frank E, Prien RF, Jarrett RB, et al. Conceptualization and rationale for consensus definitions of terms in major depressive disorder: remission, recovery, relapse, and recurrence. Arch Gen Psychiatry. 1991;48(9): 851-855.

13. Martin B Keller. Past, present, and future directions for defining optimal treatment outcome in depression. JAMA. 2003;289(23):3152-3160.

14. Thase ME. Evaluating antidepressant therapies: remission as the optimal outcome. J Clin Psychiatry. 2003;64(Suppl 13):18-25.

15. Fava GA, Ruini C, Belaise C. The concept of recovery in major depression. Psychol Med. 2007;37(3):307-317.

16. Fava GA, Visani D. Psychosocial determinants of recovery in depression. Dialogues Clin Neurosci. 2008;10(4):461-472.

17. Zimmerman M, McGlinchey JB, Posternak MA, et al. How should remission from depression be defined? The depressed patient's perspective. Am J Psychiatry. 2006;(163):148-150.

18. Slade M, Hayward M. Recovery, psychosis and psychiatry: research is better than rhetoric. Acta Psychiatr Scand. 2007;116(2):81-83.

19. McKnight PE, Kashdan TB. The importance of functional impairment to mental health outcomes: a case for reassessing our goals in depression treatment research. Clin Psychol Rev. 2010;29(3):1-40.

20. Muñoz RA, McBride ME, Brnabic AJM, et al. Major depressive disorder in Latin America: the relationship between depression severity, painful somatic symptoms, and quality of life. J Affect Disord. 2005; 86(1):93-98.

21. Curry J, Silva S, Rohde P, et al. Recovery and recurrence following treatment for adolescent major depression. Arch Gen Psychiatry. 2011; 68(3):263-269.

22. Meyers BS, Sirey JA, Bruce M, et al. Predictors of early recovery from major depression among persons admitted to community-based clinics: an observational study. Arch Gen Psychiatry. 2002;59(8):729-735.

23. Lorant V, Deliège D, Eaton W, Robert A, Philippot P, Ansseau M. Socioeconomic inequalities in depression: a meta-analysis. Am J Epidemiol. 2003;157(2):98-112.

24. Otte C. Incomplete remission in depression: role of psychiatric and somatic comorbidity. Dialogues Clin Neurosci. 2008;10(4):453-460.

25. Boland RJ, Martin B Keller. The course of depression. In: Davis KL, Charney D, Coyle JT, Nemeroff C, editors. Neuropsychopharmacology: The Fifth Generation of Progress. American College of Neuropsychopharmacology; 2002:1009-1015.

26. World Medical Association. World Medical Association Declaration of Helsinki - Ethical Principles for Medical Research Involving Human Subjects. JAMA. 2013;310(20):2191-2194. 
27. ICH Harmonised Tripartite Guideline. Guideline for good clinical practice E6(R1). ICH Harmon Tripart Guidel. 1996;1996(4):i-53.

28. Dueñas H, Lee A, Brnabic AJM, et al. Frequency of treatment-emergent sexual dysfunction and treatment effectiveness during SSRI or duloxetine therapy: 8-week data from a 6-month observational study. Int $J$ Psychiatry Clin Pract. 2011;15(2):80-90.

29. Dueñas H, Brnabic AJM, Lee A, et al. Treatment-emergent sexual dysfunction with SSRIs and duloxetine: effectiveness and functional outcomes over a 6-month observational period. Int J Psychiatry Clin Pract. 2011;15(4):242-254.

30. WHO. The ICD-10 Classification of Mental and Behavioural Disorders. Clinical Descriptions and Diagnostic Guidelines. WHO; 1992.

31. American Psychiatric Association (APA). Diagnostic and Statistical Manual of Mental Disorders. 4th ed; text revision. APA; 2000.

32. Guy W. ECDEU Assessment Manual for Psychopharmacology (Revised). 1976.

33. McGahuey C, Gelenberg A, Laukes C, et al. The Arizona Sexual Experience Scale (ASEX): reliability and validity. J Sex Marital Ther. 2000;26(1):25-40.

34. Rush AJ, Trivedi MH, Ibrahim HM, et al. The 16-Item Quick Inventory of Depressive Symptomatology (QIDS), Clinician Rating (QIDS-C), and Self-Report (QIDS-SR): a psychometric evaluation in patients with chronic major depression. Biol Psychiatry. 2003;54(5):573-583.

35. Dueñas H, Lara C, Walton RJ, Granger RE, Dossenbach M, Raskin J. The integral inventory for depression a new self rated clinimetric instrument for the emotional and painful dimensions in major depressive disorder. Int J Psychiatry Clin Pract ISSN. 2011;15(3):171-179.

36. Berwick DM, Murphy JM, Goldman PA, Ware JEJ, Barsky AJ, Weinstein MC. Performance of a five-item mental health screening test. Med Care. 1991;29(2):169-176.

37. Kroenke K, Spitzer R, Williams J. Physical symptoms in primary care: predictors of psychiatric disorders and functional impairment. Arch Fam Med. 1994;3:774-779.

38. Sheehan D, Harnett-Sheehan K, Raj B. The measurement of disability. Int Clin Psychopharmacol. 1996;11(Suppl 3):89-95.

39. Furukawa TA. Assessment of mood: guides for clinicians. J Psychosom Res. 2010;68(6):581-589.

40. Berk M, Ng F, Dodd S, et al. The validity of the CGI severity and improvement scales as measures of clinical effectiveness suitable for routine clinical use. J Eval Clin Pract. 2008;14(6):979-983.

41. Dueñas H, Lara C, Walton RJ, Granger RE, Dossenbach M, Raskin J. The integral inventory for depression, a new, self-rated clinimetric instrument for the emotional and painful dimensions in major depressive disorder. Int J Psychiatry Clin Pract. 2011;15(3):171-179.

42. Sheehan KH, Sheehan DV. Assessing treatment effects in clinical trials with the Discan metric of the Sheehan Disability Scale. Int Clin Psychopharmacol. 2008;23(2):70-83.

43. Akerblad A-C, Bengtsson F, Ekselius L, von Knorring L. Effects of an educational compliance enhancement programme and therapeutic drug monitoring on treatment adherence in depressed patients managed by general practitioners. Int Clin Psychopharmacol. 2003;18:347-354.

44. Akerblad A-C, Bengtsson F, von Knorring L, Ekselius L. Response, remission and relapse in relation to adherence in primary care treatment of depression: a 2-year outcome study. Int Clin Psychopharmacol. 2006;21(2):117-124.

45. Julius RJJ, Novitsky MA Jr, Dubin WR. Medication adherence: a review of the literature and implications for clinical practice. J Psychiatr Pract $V$. 2009;15(1):34-44.

46. Pampallona S, Bollini P, Tibaldi G, Kupelnick B, Munizza C. Patient adherence in the treatment of depression. Br J Psychiatry. 2002;180: 104-109.

47. Viinamäki H, Haatainen K, Honkalampi K, et al. Which factors are important predictors of non recovery from major depression: a 2 year prospective observational study. Nord J Psychiatry. 2006;60(5): 410-416.
48. Hong J, Novick D, Montgomery W, et al. Real-world outcomes in patients with depression treated with duloxetine or a selective serotonin reuptake inhibitor in East Asia. Asia-Pacific Psychiatry. 2016;8: $51-59$

49. Novick D, Montgomery W, Haro JM, et al. Functioing in patients with major depression treated with duloxetine or a selective serotonin reuptake inhibitor in East Asia. Neuropsychiatr Dis Treat. 2015;12: 383-392.

50. Thase ME, Entsuah AR, Rudolph RL. Remission rates during treatment with venlaxafine or selective seretonin reuptake inhibitors. $\mathrm{Br} \mathrm{J}$ Psychiatry. 2001;178:234-241.

51. Entsuah AR, Huang H, Thase ME. Response and remission rates in different subpopulations with major depressive disorder administered venlafaxine, selective serotonin reuptake inhibitors, or placebo. J Clin Psychiatry. 2001;62(11):869-877.

52. Papakostas GI, Thase ME, Fava M, Nelson JC, Shelton RC. Are antidepressant drugs that combine serotonergic and noradrenergic mechanisms of action more effective than the selective serotonin reuptake inhibitors in treating major depressive disorder? A meta-analysis of studies of newer agents. Biol Psychiatry. 2007;62(11):1217-1227.

53. Cipriani A, Koesters M, Furukawa TA, et al. Duloxetine versus other anti-depressive agents for depression Andrea. Cochrane Database Syst Rev. 2012;12:CD006533.

54. Hansen RA, Gartlehner G, Lohr KN, Gaynes BN, Carey TS. Efficacy and safety of second-generation antidepressants in the treatment of major depressive disorder. Ann Intern Med. 2005;143(6):415-426.

55. Möller HJ. Rating depressed patients: observer- vs self-assessment. Eur Psychiatry. 2000;15(3):160-172.

56. Uher R, Perlis RH, Placentino A, et al. Self-report and clinician-rated measures of depression severity: can one replace the other? Depress Anxiety. 2012;29(12):1043-1049.

57. Tada M, Uchida H, Suzuki T, Abe T, Pollock BG, Mimura M. Baseline difference between patients' and clinicians' rated illness severity scores and subsequent outcomes in major depressive disorder: analysis of the STAR*D data. J Clin Psychopharmacol. 2014;34(3):297-302.

58. Grieken RA van, Beune EJAJ, Kirkenier ACE, Koeter MWJ, Zwieten MCB van, Schene AH. Patients' perspectives on how treatment can impede their recovery from depression. $J$ Affect Disord. 2014;167: $153-159$.

59. American Psychiatric Association (APA). Practice Guideline for the Treatment of Patients with Major Depressive Disorder. 3rd ed. American Psychiatric Association; 2010.

60. Anthony WA. Recovery from mental illness: the guiding vision of the mental health service system in the 1990s. Psychosoc Rehabil J. 1993;16(4): 11-23.

61. Barber ME. Recovery as the new medical model for psychiatry. Psychiatr Serv. 2012;63(3):277-279.

62. Robinson DG, Woerner MG, McMeniman M, Mendelowitz A, Bilder RM. Symptomatic and functional recovery from a first episode of schizophrenia or schizoaffective disorder. Am J Psychiatry. 2004; 161(3):473-479.

63. Harrison G, Hopper KIM, Craig T, et al. Recovery from psychotic illness: a 15- and 25-year international follow-up study. Br J Psychiatry. 2001;178(6):506-517.

64. Angst J. Sexual problems in healthy and depressed persons. Int Clin Psychopharmacol. 1998;13(Suppl 6):S1-S4.

65. Bonierbale M, Lancon C, Tignol J. The ELIXIR study: evaluation of sexual dysfunction in 4557 depressed patients in France. Curr Med Res Opin. 2003;19(2):114-124. 


\section{Supplementary material}

Table SI The list of Ethical Review Boards (ERBs) for the BIJ-MC-B0I 9 observational study

\begin{tabular}{|c|c|}
\hline Country & ERB \\
\hline Austria & Ethikkommission für das Bundesland Salzburg \\
\hline \multirow[t]{8}{*}{ China } & First Medical College of Haerbin University \\
\hline & People's Hospital of Wuhan University \\
\hline & Second Hospital of Soochow University \\
\hline & Shandong Mental Health Center \\
\hline & Sixth University of Beijing University \\
\hline & Guangzhou First People's Hospital \\
\hline & Beijing Anding Hospital of Capital Medical \\
\hline & University \\
\hline \multirow[t]{3}{*}{ Hong Kong } & Institutional Review Board of the University \\
\hline & of Hong Kong/Hospital Authority Hong Kong \\
\hline & West Cluster \\
\hline \multirow[t]{5}{*}{ Israel } & Sheba MC \\
\hline & Shalvata Hospital \\
\hline & Rambam MC \\
\hline & Abarbanel Hospital \\
\hline & Soroka MC \\
\hline \multirow[t]{2}{*}{ Malaysia } & Medical Ethics Committee, Universiti Malaya \\
\hline & Medical Centre \\
\hline \multirow[t]{2}{*}{ Mexico } & Mexico Centre for Clinical Research Mexico \\
\hline & Centre for Clinical Research SA de CV \\
\hline \multirow[t]{6}{*}{ Philippines } & Makati Medical Institutional Review Board, \\
\hline & Makati, Luzon \\
\hline & The Medical City Institutional Review Board, \\
\hline & Ortigas Avenue, Pasig City, Metro Manila \\
\hline & St Luke's Institutional Ethics Review \\
\hline & Committee, Quezon City, Luzon \\
\hline Saudi Arabia & Medicare Specialist Clinics, Riyadh \\
\hline \multirow[t]{2}{*}{ Singapore } & National Healthcare Group Domain Specific \\
\hline & Review Board \\
\hline \multirow[t]{5}{*}{ Taiwan } & Joint Institutional Review Board, Taipei \\
\hline & National Taiwan University Hospital \\
\hline & Research Ethics Committee, Taipei \\
\hline & Institutional Review Board of Tri-Service \\
\hline & General Hospital, Taipei \\
\hline Thailand & Srithanya Hospital, Nontaburi \\
\hline United Arab Emirates & Psychiatry Hospital Abu Bhabi, Abu Dhabi \\
\hline
\end{tabular}

Patient Preference and Adherence

Dovepress

\section{Publish your work in this journal}

Patient Preference and Adherence is an international, peer-reviewed, open access journal that focuses on the growing importance of patient preference and adherence throughout the therapeutic continuum. Patient satisfaction, acceptability, quality of life, compliance, persistence and their role in developing new therapeutic modalities and compounds to optimize clinical outcomes for existing disease states are major areas of interest for the journal. This journal has been accepted for indexing on PubMed Central. The manuscript management system is completely online and includes a very quick and fair peer-review system, which is all easy to use. Visit http://www. dovepress.com/testimonials.php to read real quotes from published authors. 